\title{
Para superar as prescrições direcionadas ao professor de física
}

To over come the prescriptions addressed to physics teachers

\author{
Maria José P. M. de Almeida
}

Grupo de Estudo e Pesquisa em Ciência e Ensino - gepCE Faculdade de Educação - FE Universidade Estadual de Campinas - UNICAMP Campinas SP Brasil. Pesquisadora do Conselho Nacional de Desenvolvimento Cient́fico e Tecnológico CNPq. Email: mjpma@unicamp.br

Recibido: 26-04-2009

\section{Resumo}

Neste estudo partimos da consideração da relevância da autonomia do professor na organização das relações de ensino de que participa em sala de aula. Como prescrições dirigidas ao professor se opõem à possibilidade de autonomia, buscamos compreender manifestacoões de caráter prescritivo visando contribuir para a diminuição de sua ocorrência. Para tanto, nos apoiamos numa vertente da análise do discurso para compreender como, em certas condições de produção, prescrições, explicitas ou implícitas, são direcionadas a professores de física da educação básica. Os discursos analisados foram obtidos em periódico, ata de encontro e através de entrevistas e questionário. Todos foram formulados em situações relacionadas com o ensino da física, no Brasil, em diferentes momentos desde a segunda metade do século passado. Entre as considerações que o estudo permite inferir, destaca-se a contribuição da participação na área de educação em ciências na superação das prescrições.

\section{Palavras chave}

Ensino de Física, Formação de Professores, Prescricões, Análise de Discurso.

\section{Abstract}

This Study was carried out with the consideration of the teachers' autonomy relevance in the teachers' relations organization he participates in the dassroom. Prescriptions addressed to the teacher are opposed to the possibility of autonomy. We intended to contribute to the decrease of the prescriptions by understanding prescription's ocaurrences. The theoretical support to investigate impliait or explicit prescriptions are addressed to the high school teachers in determined production conditions was one of the lines of the discourse analysis. Analyzed discourses were obtained from a periodic, a congress proceeding, interviews and questionnaire. Every Discourse was formulated in situations related with physics teaching, in Brazil, in different moments since the last middle of past century. Among the considerations the study permits to infer, we show up the contribution of the science education area to prescriptions overcoming. 
Tecné, Episteme y Didaxis: TE $\Delta$ No. Extraordinario, 2009

$4^{\circ}$ Congreso Internacional sobre Formación de Profesores de Ciencias

Conferencias Centrales

Keywords

Physics Education, Teachers Training, Prescriptions, Discourse Analysis.

\section{Introdução e justificativa}

Dada a incontestável importância do professor quando pensamos no trabalho escolar em qualquer nível de ensino, da pré-escola à educação superior, parece justificar-se a imensa quantidade de recomendações que a ele têm sido dingidas implícita ou explicitamente. Elas estão presentes na literatura sobre educação em diferentes gêneros: jomais, boletins, periódicos, guias para textos didáticos, etc. E, em alguns casos, essas recomendações deixam de ser simples conselhos ou advertências para se transformarem em verdadeiras prescricões.

A prescrição é aqui entendida como: dizer ao professor o quê, quando e como trabalhar com seus alunos. 0 que lhe resta então? Ser o animador de um auditório no qual ele expõe conhecimentos prescritos pelos que se consideram e são considerados especialistas no ato de ensinar. Eles encarregam-se de estabelecer a matéria que o professor deve passar aos alunos e também determinam como ele deve fazê-lo.

Por sua divulgação como verdades inquestionáveis, as prescrições freqüentemente fazem parte do imaginário tanto de quem as divulga quanto daqueles a quem elas se destinam, eliminando possibilidades de atuação autônoma destes últimos.

A compreensão da posição do professor no contexto social em que ele se localiza é um fator relevante a ser considerado se quisermos compreender a natureza das recomendações que lhe são dirigidas. É interessante lembrar que, como profissional, ele ocupa um lugar especializado na sociedade, um lugar de caráter intelectual, conforme nos alerta (Ianni , 1986):

[...] os intelectuais que estão nas atividades de docência e de pesquisa, e mesmo em atividades técnicas, estão, por assim dizer, determinados pela condição de intelectuais orgânicos, no sentido de que entram na produção aultural, ou na reprodução aultural de valores, ideais, padrões, conceitos, metáforas, imagens, propostas, projetos, planos, visóes de mundo, que entram na máquina da sociedade e fazem parte do jogo das forças sociais em luta, no âmbito da sociedade [...] p.49.

O resgate do professor da condição de mero cumpridor de tarefas que foram organizadas previamente, mas não por ele, não é uma idéia nova. Autores como Henry Giroux, Joe Kincheloe e José Contreras, são três dos muitos autores que se dedicaram em seus estudos a pensar a função docente. Publicações suas do final da década passada evidenciam bem o quanto eles se afastaram de posicionamentos que assumem a possibilidade de se fazer prescricões aos profissionais do ensino. De maneira bastante sintética podemos dizer que em (Giroux, 1997) o professor é um intelectual, bem no sentido do que já apontamos na voz de Otávio Ianni; já em (Kincheloe, 1997) o autor nos remete para o compromisso político do professor, enquanto que (Contreras, 1999) lembra-nos da autonomia que esse profissional deve ter.

Com base em posições como as aqui citadas, podemos notar que, em grande parte das pesquisas que hoje focalizam a formação continuada de professores são desenvolvidas parcerias, ou seja, são montados projetos de investigação em que atuam, estudando e pesquisando em conjunto, profissionais do ensino básico e da universidade. $\mathrm{E}$, o mais relevante nessas pesquisas é que os procedimentos de que eles se servem para obter resultados que possam responder as questões que se propuseram a resolver consideram os diferentes saberes dos parceiros.

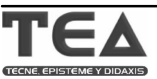


Entretanto, o trabalho em parceria não é o único possível, e prioritariamente é preciso reconhecer que a disseminação de recomendações e prescrições dirigidas ao professor tem no seu bojo o reconhecimento da importância do seu desempenho nas relações de ensino, qualquer que seja a situação educacional que se pretenda estabelecer no âmbito escolar. Mas a natureza mutável, o pouco aprofundamento e a ausência das condições de produção do que é recomendado fazem com que, muitas vezes, as recomendações não sejam contribuições efetivas para o trabalho do docente. Assim, julgamos relevante reconhecer e analisar criticamente a natureza das recomendações que são dirigidas ao professor. Nesse sentido, focalizamos essa temática direcionando-nos para a educação em ciências, em especial no que diz respeito ao professor de física da educação básica.

São inúmeros os trabalhos voltados para a formação docente no ensino de ciências, o que evidencia a importância que os pesquisadores da área têm atribuído a essa temática. Entre as publicações feitas no Brasil, citamos aqui: (Krasilchik;1987); (Carvalho e Pérez; 1993); (Menezes; 1996); (Gioppo; 1999); (Mion e Saito; 2001); (Selles e Ferreira, 2003); (Nardi et al; 2004); (Rosa; 2004). Citações essas que ilustram, mas não esgotam o grande número de estudos com direcionamentos diversificados e sustentados em diferentes apoios teóricos. No entanto, acreditamos que a complexidade das relações de ensino que ocorrem em sala de aula, bem como a enorme possibilidade de seleção de conteúdos diversificados, além das estratégias e dos recursos, que podem ser utilizados numa aula, fazem com que mesmo podendo contribuir significativamente para que ocona um ensino de boa qualidade, as pesquisas da educação em ciências não têm, não terão, e nem seria conveniente que viessem a ter, respostas unívocas para resolver questões do ensino nas disciplinas que a constituem. Ou seja, as recomendações não poderão indicar um caminho único para que o professor o siga. E aqui estamos considerando indusive a hipótese irrealizável de que fossem levadas em conta as recomendaģões já divulgadas, e as que ainda deveriam ser incorporadas se fossem ouvidos todos aqueles que julgassem conveniente recomendar algo aos professores. O fato é que, estes sempre estarão sujeitos a novos acontecimentos decorrentes das interações e interloạcões de que participam em seu dia a dia profissional.

Também é preciso que admitamos o fato de que tanto as prescrições quanto as recomendações aos professores têm sua origem em posições de quem as verbaliza. Posições que não são todas idênticas. No entanto, se, por um lado, é fato que continuaremos a conviver com múltiplos olhares sobre como deve ser o ensino e o trabalho docente, também é fato que continuarão sendo disseminados diferentes pontos de vista sobre maneiras de ensinar e sobre o que deve e o que não deve ser ensinado. Mas, por outro lado, consideramos absolutamente necessário que sejam superadas as prescrições.

Tendo em vista a descrença na sua utilidade como perspectiva para mudanças eficazes no ensino, independentemente delas serem dirigidas direta ou implicitamente ao professor, neste estudo buscamos contribuir para a diminuição de sua ocorrência. Nesse sentido, analisamos discursos explicita ou implicitamente direcionados a professores da educação básica. Todos os discursos analisados foram formulados em condições de produção relacionadas com o ensino da física no Brasil, e fazem parte de estudos realizados em diferentes momentos desde a segunda metade do século passado.

\section{Apoio Teórico}

A concepção de linguagem e as noções teóricas em que nos apoiamos para desenvolvimento deste texto procedem de uma das vertentes da análise do discurso, na qual devemos admitir principalmente a noção de discurso compreendida como efeito de sentidos entre locutores. 
Recorremos principalmente a trabalhos publicados no Brasil por Eni Orlandi, o que nos leva a assumir a não transparência da linguagem. Ou seja, ao nos apoiarmos nesta vertente da análise do discurso, assumimos que não faz sentido perguntarmos o que isto ou aquilo significa. Nossas questões são do tipo: como estes dizeres foram produzidos? Essa questão nos remete para as condições de produção dos dizeres com a caracterização dessas condições como não sendo apenas as imediatas e próprias das situações discursivas em que selecionamos os disaursos. Precisamos admitir que, além das condições imediatas, a linguagem subentende condições de produção sóciohistóricas, e também considerar que, além das condições materiais, toda compreensão de um discurso supõe a existência de condições imaginárias.

Nessa vertente, a linguagem constitui a materialidade do discurso e ao estudá-la não podemos ter em conta apenas a sua estrutura, mas também os acontecimentos dos quais ela constitui a materialidade a ser analisada.

Outra noção necessária para compreensão da linguagem na vertente da análise de discurso a que estamos nos referindo é a de ideologia. Em (Orlandi, 1995) a autora afirma a relação da ideologia com a produção de um imaginário, entendido como uma interpretação espećfica entre muitas outras possíveis; interpretação essa que, no entanto, aparece para o falante/ouvinte como interpretação necessária, sendo a ideologia compreendida como o mecanismo de produção dessa interpretação:

Se não nos ativermos aos conteúdos da linguagem, podemos procurar entender 0 modo como os textos produzem sentidos e a ideologia será então percebida como 0 processo de produção de um imaginário, isto é produção de uma interpretação particular que apareceria, no entanto, como interpretação necessária e que atribui sentidos fixos às palavras, em um contexto histórico dado. p.65.

E a autora, além de dizer que a ideologia não é um conteúdo e sim o mecanismo de produzi-lo, para melhor caracterizar a ideologia como é concebida nessa vertente da análise de discurso, acrescenta que, como os sujeitos estão condenados a significar, a interpretação é sempre regida por condições de produção espećficas que, no entanto, aparecem como universais e etemas. Disso resultaria a impressão do sentido único e verdadeiro. E para evidenciar como o sentido que aparece como único e verdadeiro é, na realidade, resultado de uma interpretação ideologicamente orientada, a autora ainda nos lembra que um dos efeitos ideológicos está na negação da própria interpretação. Ou seja, Orlandi aponta que, para o sujeito que produz sentidos ao interpretar, esses sentidos não aparecem como produtos de uma interpretação, mas sim como transparência. Em outros termos, cada interpretaçao aparece para quem interpreta como sendo a única possível.

Por outro lado, quando se refere à noção de relações de força e a formações imaginárias a autora nos permite dizer que o lugar a partir do qual o sujeito fala é constitutivo do que ele diz Ou seja, se o sujeito fala a partir do lugar de professor, suas palavras significam de modo diferente do que se falasse do lugar do aluno. E como nossa sociedade é constituída por relações hierarquizadas, são relações de força, sustentadas no poder desses diferentes lugares, que fazem com que o que é dito tenha valores diferenciados.

Com relação ao mecanismo imaginário, Orlandi (1999) aponta para o seu funcionamento ao dizer que:

[...] Esse mecanismo produz imagens dos sujeitos, assim como do objeto do discurso, dentro de uma conjuntura sócio-histórica. Temos assim a imagem da posição sujeito locutor (quem sou eu para lhe falar assim?) mas também da posição sujeito interlocutor (quem é ele para me falar assim, ou para que eu lhe fale assim?), e também a do sujeito do discurso (do que estou lhe falando, do que ele me fala?). É pois todo um jogo imaginário que preside a 
troca de palavras. E fazemos intervir a antecipacão, [...] a imagem que o interlocutor faz da imagem que ele faz do objeto do disaurso e assim por diante. [...] Na relação discursiva, são as imagens que constituem as diferentes posigóes. p.40

E ainda, conforme Orlandi (1983):

[...] os interlocutores, a situação, o contexto histórico-social (i. é., as condigấes de produção) constituem o sentido da seqüência verbal produzida. Quando se diz algo, alguém o diz de algum lugar da sociedade para outro alguém também de algum lugar da sociedade $e$ isso faz parte da significação. Como é exposto por Pêcheux, há nos mecanismos de toda formacão social regras de projeção que estabelecem a relação entre as situaçães concretas $e$ as representagóes dessas situacóes no interior do disaurso. É o lugar assim compreendido, enquanto espago de representagóes sociais, que é constitutivo da significação disaursiva. [...] faz parte da estratégia discursiva prever, situar-se no lugar do ouvinte (antecipação das representagóes), a partir de seu próprio lugar de loautor, o que regula a possibilidade de respostas, o escopo do discurso.p. 19.

Essas considerações, associadas à não transparência da linguagem, o alicerce em que se funda a análise do discurso na vertente aqui considerada, implicam no fato de que o sentido das palavras não é um dado a ser descoberto. Para compreendê-lo é preciso por as palavras em relação com outras palavras e não há garantias sobre os sentidos produzidos numa interlocução, pois nem os sujeitos nem os sentidos são evidentes.

\section{Um Discurso Revelador}

Nesta seção, com base em elementos do apoio teórico apresentado no item anterior, vamos comentar um discurso que pode ser confundido com uma proposta de parceria. Ele aponta para um trabalho conjunto entre professores da escola básica e professores universitários, mas manifesta 0 oposto do que seria uma efetiva parceria:

[...] Contrariamente ao que se ouve ocasionalmente, o projeto PSSC foi um esforco conjunto de professores da universidade e do ensino médio. Cada grupo contribuiu com suas habilidades. Coube aos físicos com domínio completo da área desenvolver uma nova estrutura e novas abordagens. Coube a professores competentes certificar-se de que o nível era apropriado, testar o material em sala de aula e fornecer os resultados. HABER-SCHAI, Uri. Reform in Science Education: Then and Now. The Physics Teacher, New York, v.36, n.5, maio 1998 p.295p.295.

Haber-Shai, o autor desse discurso, foi nos anos cinqüenta do século passado nos Estados Unidos da América um dos principais elaboradores do projeto a que ele se refere, destinado ao ensino da física no nível médio. Neste discurso já do final dos anos noventa podemos notar como em seu imaginário o professor da escola básica é um mero aplicador daquilo que caberia aos professores da universidade desenvolver.

Não é nossa intenção propor ou fazer dassificações neste texto, mas acreditamos que valha a pena lembrar aquela que foi feita para as chamadas tendências pedagógicas não críticas, bastante divulgada no Brasil nos anos oitenta: tradicional; nova e tecnicista. De maneira sintética podemos afirmar que, na primeira o professor é considerado aquele que sabe; já na escola nova ele passa a ser um orientador e no tecnicismo pedagógico ao professor é destinada a aplicação daquilo que outros, os chamados especialistas, produziram (Almeida, 1989).

O exemplo aqui referido se enquadra muito bem no teanicismo pedagógico, em cuja maneira de conceber as relações de ensino caberia ao especialista pensar o que deve e o que não deve ser 
ensinado. Também seria competência do especialista a seleção das estratégias e dos reaursos a serem utilizados no ensino, ficando para o professor o papel de aplicar o que outros pensaram ser o adequado. Neste exemplo, os professores da universidade seriam os especialistas e os da escola básica seriam os aplicadores.

\section{Discursos anteriores a formação da área de educação em ciências}

É fato que, no Brasil mesmo antes do início da divulgação de produções consideradas como investigações da área de educação em ciências, alguns eventos analisados a partir do que se conhece hoje, contribuíram de maneira muito significativa para processos que culminariam com a legitimação dessa área de investigação. Um deles foi, sem dúvida, a realização de simpósios nacionais de ensino. O primeiro Simpósio Nacional De Ensino De Física - SNEF, ocorreu em 1970. Nas atas desse simpósio podemos encontrar textos de seus participantes que indicam a diversidade de posições com relação ao que poderia ser considerado o papel do professor. Como exemplo dessa diversidade, apresentamos dois discursos sobre o projeto citado no item anterior, que havia sido traduzido no Brasil. Nesses dois discursos também podemos subentender a diversidade de posições em relação à atuação do professor da escola básica, e conseqüente natureza das recomendações que supostamente lhe seriam dirigidas.

No primeiro discurso podemos ler:

[...] se você não puder comprar os carninhos importados, que custam alguns dólares ou não puder comprá-los no IBECC que procura fabricá-los ao menor preco possível, ponha três rodas num tjjolo ou num pedaco de pau, e tente fazer. A grande lição do PSSC é justamente esta: a ciência é processo de aproximação gradativa; não diz que aquilo só é possível com todo o equipamento, com todos os filmes, com todas as condiçóes ideais, não se disse isso! Talvez, a maior ou pelo menos, uma grande lição do PSSC é a de mudança de atitude. Acho que a ninguém pode ocorrer dívida de que para esta mudança de atitude, o PSSC foi, senão a causa única, pelo menos a 'célula mater'. O desenvolvimento dessas idéías se deu em torno do trabalho que se fez com o PSSC; não foi o PSSC que salvou a América, nem que salvou o ensino, mesmo porque ele não está salvo, mas que certamente nos lembrou que 0 que estávamos fazendo, em Física, era semelhante a dar cursos de natação por correspondência. [...]. CANIATO, Rodolfo In SOCIEDADE BRASILEIRA DE FÍSICA. Simpósio Nacional Sobre O Ensino Da Física. Salvador, Boletim n.4, 1970. p.71-74.

Já num trecho da fala do outro participante podemos ler:

[...] Não acho que o PSSC deva ser adotado ou imitado, ou ensinado, de jeito nenhum. Acho mesmo, como sempre dedarei, quando solicitado, quando me perguntavam - 'mas 0 senhor acha que o PSSC é a solução?' - Não, não acho uma solução. Não há uma solução, há solucôes. Não vejo necessidade nenhuma de o professor adotar este ou aquele curríallo, desde que tenha consciência do papel que deve representar na formação do jovem do adolescente; desde que tenha um conhecimento razoável da matéria, isto é, desde que seja um bom profissional. Muito mais importante que o PSSC ou qualquer outro culníallo que venha a aparecer, é a atitude do professor; muitíssimo mais importante é a compreensão do relacionamento entre professor e aluno. Para isso, evidentemente, vamos tocar em problemas que sáo aparentemente insolúveis. A primeira coisa a fazer, é obviamente transformar um 'estado de coisas' em profissão, eu me explico. Atualmente, o professor de ensino seculndário, particularmente em Física, não é profissão, é 'estado', desculpem-me a palavra, estado do 'burro de carga'. Obviamente, não se pode esperar de quem dá 40 a 50 aulas por semana para poder sobreviver, que tenha, além disso, cabeça tranquitla para pensar nos problemas, para amadurecer esses problemas, para pensar num modo de apresentá-los. Não acho que isso seja possível, por enquanto, e não acho também que a 
adocão de qualquer novo aurníalo possa operar milagres. Pierre Lucie In SOCIEDADE BRASILEIRA DE FÍSICA. Simpósio Nacional Sobre 0 Ensino Da Física. Salvador, Boletim n.4, 1970. p.68-71.

No primeiro discurso, o autor, embora não se dirija explicitamente ao professor, parece falar com ele da posição de alguém que vê na experimentação uma possibilidade segura para melhoria do ensino. O projeto PSSC (Physical Science Study Committee, que havia sido traduzido e publicado no Brasil) lhe daria a autoridade para falar no tom prescritivo que podemos notar nesse discurso. Já o segundo autor, descarta o PSSC como solução para os problemas do ensino; aponta para a multiplicidade de soluções, sem, entretanto, descartar a relevância do papel do professor. Ou, mais especificamente, das suas atitudes. Por outro lado, sua fala também evidencia a não aceitação da situação do ensino naquele momento, e aponta as condições de produção do trabalho do professor como causa dessa situação.

Vejamos agora um discurso presente no manual do professor de um projeto de ensino produzido no Brasil alguns anos após o referido simpósio. A possibilidade de realização de projetos brasileiros havia sido amplamente disautida no simpósio.

Professor: - É o centro do sistema educacional. Ele é a fonte do saber, transmissor de conheaimento, atitudes e valores. Tudo é feito através dele. Funcaáo básica: dar e tomar ligóes. Tal esquema leva a situacóes típicas tais como: Aulas e orientacóes coletivas; Aluno ouvindo ou escrevendo ou perguntando (às vezes); Avaliação coletiva dentro de certos calendários nígidos com fins burocáticos simplesmente; Pressuposição de que todos os alunos aprendem de forma idêntica e apresentam os mesmos pré-requisitos; Passividade por parte do aluno. GETEF. Física FAI Auto-Instrutivo: Texto Programado Para 20 Grau Manual do Professor. São Paulo: edição Saraiva, 1973. 19p. p.6.

Esse discurso é uma cítica dos autores do projeto à escola tradicional, o que poderia pressupor uma perspectiva de maior autonomia para o professor. No entanto, a característica básica dos recursos produzidos nesse projeto, textos com conteúdos na forma de instrução programada, supõe que cada aluno caminhará na leitura do texto no seu próprio ritmo, cabendo ao professor apenas tirar dúvidas ou eventualmente ensinar algo a algum aluno que manifeste interesse em determinado aspecto do conteúdo. Vemos assim a pouca autonomia que restaria para o docente caso esse fosse o projeto adotado.

Com esse exemplo, podemos notar que, se o professor tiver que utilizar determinados recursos didáticos sem ter tido autonomia para decidir com fundamentação se os utilizaria ou não, a própria natureza dos recursos em questão pode subentender um direcionamento altamente prescitivo. Por outro lado, é interessante notarmos que o papel atribuído ao professor no contexto educacional brasileiro aparentemente tem estado bastante associado não apenas ao imaginário de quem pensa esse papel, mas também a condições que em determinados momentos parecem deter o poder de resolver os problemas do ensino. Nesse sentido, de acordo com (Almeida, 2003):

Com relação às preocupaçães com os professores de fisica no ensino médio, sínteses obtidas a partir de entrevistas realizadas em 1975, [...] fizeram compreender que, 0 envolvimento com os projetos de ensino nas décadas de 60 e 70 contribuiu para desfocalizar o imaginário dos que tinham oportunidade de pensar o ensino de fisica em grau médio unicamente do professor, com intuitos muito diferenciados, aparentemente associados à difiusão ideológica associada a dois projetos, o PSSC e o Projeto Piloto, ambos gerados fora do Brasil, tendo um sido aqui desenvolvido e o outro traduzido. Os dois apresentando conceppóes de qual fisica e de que maneira ensiná-la bastante divergentes. p.87 
No mesmo trabalho há referência a um estudo realizado em 1990 a partir de um questionário respondido por professores de física no nível superior numa universidade pública, na qual havia um curso de formação de professores, mas onde todos os docentes entrevistados pesquisavam em áreas diferentes da de ensino. Entre as condusões desse estudo, podemos ler que:

[...] na referência a expectativas de contribuição do professor de ensino médio, foram feitas algumas cuíticas às vezes enunciadas de maneira bastante contundente, tais como: ['...] saber física, que nem sempre é o caso'; [...] se sério o professor deve [...]'; ou críticas à atuação do professor, que segundo o pesquisador, leva o aluno a pensar que física é 'um conjunto de fórmulas' Um professor ainda, ao responder a questão sobre 0 professor de ensino médio referiu-se a 'vivência' do professor, referindo-se a saber pesquisar, 0 que segundo ele '[...] não se aprende na escola, mas na vida'.p.90.

Além de, em alguns casos, a prescrição ser bastante explicita: "[...] o professor deve [...]", aparentemente para o conjunto de docentes entrevistados o único critério balizador do seu imaginário sobre o que deveria ser um bom professor de física do ensino médio estava associada à própria física. E naquele estudo também foi notada a perspectiva daqueles docentes de verem na física do ensino médio apenas a preparação para o ensino superior.

\section{Discursos no contexto de pesquisas na educação em ciências}

Neste item, vamos analisar discursos obtidos em entrevistas a pesquisadores da área de educação em ciências realizadas em dois momentos bastante distintos.

Inicialmente, analisamos discursos obtidos através de entrevistas a pesquisadores da área de educação em ciências em 1996. Todos os entrevistados lecionavam em universidades públicas no Estado de São Paulo, Brasil, em aursos de formação de professores de física ou estavam desenvolvendo projetos de pesquisa sobre a formação desses professores naquelas universidades. A entrevistadora, autora do presente texto, realizou a entrevista como parte de um projeto que tinha como um de seus objetivos: compreender o que levava alguém a pesquisar a formação de professores.

No seguinte discurso de um dos docentes entrevistados, um fragmento de sua resposta para uma pergunta direta sobre o que o tinha levado a pesquisar a formação de professores, não notamos uma perspectiva de parceria, mas sim dele levar algo para professor do ensino médio:

[...] entrei para transpor esse conhecimento de um fórum, que é o fórum da universidade para a sala de aula dos professores.

Já no discurso a seguir notamos, se não uma perspectiva explicita de parceria, o reconhecimento de dificuldades e da necessidade de diálogo com o professor de ensino médio:

[...] é a minha história, eu tenho trabalhado na parte pesquisa e ensino com as representagóes espontâneas, com o problema das estratégias que possam favorecer essas mudancas. Primeiro passo foi tentar fazer com que esses resultados passassem para, foi natural pensar que esses resultados servissem para os professores e o efeito desse desejo de tentar influenciar o trabalho dos professores via publicacóes, esbarrou com o fato que os próprios professores têm representaçóes que às vezes são conflitantes com as que você está propondo como altemativa, mais do que isso é que o próprio diálogo com os professores não é trivial no sentido de ter uma formação comum [...]. Me parece que se você quer que alguma coisa do que você faz passe para prática, você vai ter que passar por isso, passar pelo trabalho com os professores. [....]. 
As mesmas entrevistas realizadas em 1996 e analisadas em (Almeida, 2003) comportaram mais uma questão de interesse para a problemática aqui analisada, as prescricõos dirigidas aos professores de física do ensino médio. A questão referia-se a qual podia ser a contribuição do professor de ensino médio para os processos de ensino e de aprendizagem Reproduzimos a seguir uma condusão daquele estudo, a qual indui as respostas a essa questão e engloba as obtidas para a questão sobre o que levara os pesquisadores a trabalharem com formação de professores:

Como em outras falas analisadas, de outros momentos, e a partir de outras provocacóes, as aqui registradas, fragmentos de respostas a apenas duas questóes, e lembro que formuladas na segunda metade dos anos 90 por pesquisadores da educaçáo em ciências, preocuppados com a formação de professores de física, revelam imaginários divergentes, sobre para quê ensinar física, e diferentes tendências pedagógicas. Estas indusive abrangendo um espectro tão aberto que não seria difíal mostrar falas coerentes com escolas de pensamento antagônicas. p.94.

Ressaltamos aqui uma diferença muito significativa em relação à perspectiva analisada no item anterior, relativa a uma entrevista realizada naquela mesma década, vários anos antes, com pesquisadores em outras áreas da física que não a de ensino. Enquanto, para aqueles pesquisadores, aparentemente apenas a própria física balizava suas respostas, nas falas dos pesquisadores em ensino a diversidade é abrangente a concepcões de natureza pedagógica.

Naquele estudo, também pudemos inferir, a partir da diversidade notada entre posições dos pesquisadores em formação de professores, que essa diversidade revela diferentes formações ideológicas, ou seja, o imaginário dos pesquisadores não se originou no momento da entrevista. Partindo dessa reflexão, pensamos em possíveis implicações da circulação de idéias e levantamos uma situação geradora de um questionamento. Nesse sentido, supusemos que um estudante num curso de formação de professores certamente tem durante a sua formação contato com muitos discursos que subentendem imaginários tanto ou mais contraditórios do que aqueles que ali estavam sendo analisados. E então, a partir dessa situação hipotética formulamos a seguinte questão: "[...] Como esperar que quando professor ele vá seguir recomendações associadas a um único desses imaginários, sem que para tal tenha oportunidade de refletir sobre a origem de tais recomendações?"p.95

Essa questão se relacionava estritamente com o intuito de contribuimos para a reflexão sobre a relevância de serem superadas tanto as prescriçẽes quanto as recomendações vazias dirigidas ao professor. Repetimos aqui que, a questão então formulada supondo um estudante, ou seja, alguém em formação inicial, também se aplica aos professores em exerćcio. Tal suposição admite apenas a diversidade e a grande circulação de idéias em cursos de educação continuada e também na mídia.

Mas voltando ainda àquele estudo, com ele pudemos notar o quanto os pesquisadores da área de educação em ciências entrevistados haviam superado a suposição de que os problemas do ensino da física em nível médio poderiam ser resolvidos pela simples prescrição do que os professores da educação básica deveriam fazer. Além disso, nenhum deles manifestou qualquer indício de pensar a "substituição" do professor pelo uso de recursos didáticos adequados como ocorrera com alguns entrevistados em 1975. E a maior contribuição para que isso fosse notado veio da análise das respostas relativas a uma pergunta sobre a contribuição da pesquisa em ensino de ciências para a formação de professores. É fato, contudo, que as divergências no imaginário dos pesquisadores quanto às contribuições da pesquisa para a formação de professores foram bastante grandes com apenas um entre dez entrevistados admitindo essa contribuição sem qualquer restrição. 
Passamos agora para discursos que foram também obtidos através de entrevistas, mas já nos anos 2000. Os pesquisadores entrevistados eram da área de educação em ciências com especificidade em ensino de física. As entrevistas em questão foram parte de uma ampla investigação que buscou compreender os discursos de investigadores da área de educação em ciências quando questionados sobre fatores que haviam contribuído para a constituição da educação em ciências e também para compreender quais eram suas posicões sobre quais eram as características dessa área enquanto área de pesquisa.

Os entrevistados haviam sido os mais indicados por seus pares, consultados através de correio eletrônico. Do ensino de física foram entrevistados 13 pesquisadores atuando em instituições localizadas em diferentes regiões no Brasil. Todos tinham tido oito ou mais indicações. Também foram entrevistados no mesmo estudo sete pesquisadores do ensino de química, três do de biologia e um de geociências. Apesar desse trabalho já ter sido amplamente divulgado, entre outros em trabalhos como (Nardi e Almeida, 2007 e 2008), parece-nos interessante fazer aqui uma pequena síntese dos principais fatores que teriam contribuído para a formação da área no Brasil e também das principais características indicadas.

0 espectro de fatores que teriam dado origem à área, apontados pelos pesquisadores foi bastante amplo: a existência de instituições como o Instituto Brasileiro de Educação, Ciência e Cultura IBECC, da Fundação Brasileira para o Desenvolvimento do Ensino de Ciência FUNBEC, dos Centros de Ciências, os projetos de ensino traduzidos e aplicados no país; o papel das faculdades de educação nos anos 70; políticas públicas de fomento à pós-graduação no exterior nos anos 70 e 80; a criação de pós-graduações em ensino de física no Brasil nos anos 70; projetos de ensino desenvolvidos no país; o papel de sociedades cient́ficas; o início de eventos espeáficos, como os Simpósios Nacionais de Ensino de Física; ações de determinados indivíduos, citados pelos pesquisadores, e a gênese dos periódicos da área.

As características indicadas como sendo características da área e as controvérsias em tomo delas também foram bastante diversificadas: inter e/ou multidisciplinaridade da área; caráter de pesquisa aplicada ou pesquisa e desenvolvimento; dassificação como ciências humanas ou sociais; concepcões de pesquisa mais ou menos relacionadas a modelos vindos do exterior; lócus da pesquisa mais próximo à área de "conteúdos" ou da educação, e diversidade de perspectivas em termos de objetos, apoios teóricos, procedimentos metodológicos de pesquisa e consequientes "resultados/recomendações".

Dada a representatividade dos pesquisadores entrevistados e a diversidade de fatores e características que notamos na breve síntese apresentada nos dois últimos parágrafos podemos notar que os imaginários dos pesquisadores em ensino de ciências estavam longe da unanimidade em muitos aspectos relacionados à pesquisa.

Nessa mesma investigação, a todos os pesquisadores entrevistados foi feita uma questão complementar: a formação e o crescimento da área de ensino de ciências têm interferido na maneira como se formam professores no Brasil? Por quê? (para respostas negativas) De que maneira? (para respostas positivas). Apresentamos a seguir discursos de dois pesquisadores do ensino da física ao responderem a questão:

[...] não se pode pensar que vai ser a área, ou a pesquisa em Ensino de Ciências, que vai ser responsável pela formação de professores. [...] essas questões educacionais são coisas de política governamental. [....] 0 professor vai ter um salário digno, ou ele vai continuar trabalhando 50 horas por semana? Não adianta fazer mil pesquisas, enquanto tiver professor dando 50 horas por semana. [...] não tem pesquisa, não tem área consolidada que vá contribuir pra isso, se não tiver uma política governamental. 
[...] eu acho que é um pouco difíil ainda... ele (o professor) está sobrecarregado de uma... de um discurso comercial, dos colegas que querem aprovação no vestibular e veèm, que tem que dar o programa todo, em determinados esquemas, com determinadas apostilas.... [...] Então, esse trabalho de pesquisa... de entendimento de como o aluno está ... como é que ele está desenvolvendo, essa... esse conhecimento dele.....um trabalho mais ligado à aprendizagem significativa... Isso acaba não... não tendo tempo de chegar à sala... a maioria da salas de aula, mas, eu acho que... que a gente tem casos com êxito.

Essas duas falas são bastante representativas das respostas obtidas nesse estudo para a questão sobre interferência da pesquisa na maneira como se formam professores no Brasil. Os discursos dos dois pesquisadores aqui reproduzidos se referem à educação continuada, ou seja, à formação de professores já em exerácio e não chegam a pensar a educação inicial. Ao falarem da interferência da pesquisa, eles evidenciam estar pensando no professor de física do ensino médio, e podemos notar nessas falas posições indicativas de reflexão sobre fatores externos intervenientes no trabalho desse professor. Não há nelas indícios de que no imaginário desses pesquisadores a responsabilidade direta pela não interferência da pesquisa na sala de aula seja atribuída ao professor.

Aparentemente, os pesquisadores que produziram esses discursos dificilmente assumiriam posições prescritivas em relação ao professor da escola básica.

\section{Considerações finais}

Ao longo deste texto apresentamos alguns discursos nos quais procuramos indícios de prescrições dirigidas a professores de física da escola básica. Nesse sentido, buscamos discursos formulados em situações que admitimos serem favoráveis a manifestações dessa natureza por quem os formulou. Consideramos que os vários discursos apresentados, que foram formulados em diferentes momentos e condições de produção, são bastante ilustrativos do imaginário dos entrevistados sobre a adequação ou não de manifestações prescritivas direta ou indiretamente dirigidas aos professores da educação básica.

Também admitimos que, a leitura desses exemplos possa contribuir para a interpretação de outros semelhantes e para a reflexão sobre a conveniência ou não da sua formulação, principalmente quando se pretende contribuir para mudanças efetivas no ensino escolar. A superação de ideologias que não consideram o caráter intelectual do trabalho docente, certamente está associada à superação das prescrições dirigidas ao professor.

Além disso, tomando como marco delimitador a participação em pesquisas da área de educação em ciências, pudemos notar diferenças que consideramos significativas entre discursos formulados por pesquisadores e não pesquisadores dessa área. No entanto, essa não pode ser considerada uma regra geral.

Entre os discursos comentados que foram formulados antes mesmo que se pudesse dizer que existia a área de pesquisa de ensino de ciências apresentamos os seguintes discursos associados a imaginários prescritivos: um selecionado nas atas do primeiro Simpósio Nacional de Ensino de Física de 1970 e um de guia do professor de projeto nacional de 1973. Mas também apresentamos um discurso formulado no mesmo simpósio como exemplo de discurso que não envolvia prescrições. E, por outro lado, comentamos discursos prescritivos posteriores à consolidação da área e educação em ciências: discursos de físicos não envolvidos com a pesquisa em ensino de física em 1990 e um discurso publicado em periódico de 1998, formulado por um dos elaboradores de um projeto traduzido no Brasil nos anos 60. 
Certa tendência a não focalizar o professor no centro das preocupações com o ensino foi evidenciada com discursos de 1975, período em que tinham sido produzidos ou estavam sendo produzidos projetos nacionais de ensino e alguns grupos chegaram a pensar que bons recursos didáticos poderiam de algum modo "substituir" o professor.

Já no que se refere a discursos produzidos por pesquisadores do ensino de ciências envolvidos com a formação de professores, apontamos com um discurso de 1996, que no imaginário do pesquisador que formulou esse discurso, aparentemente o que se faz em pesquisa deveria ser levado para a sala de aula. Essa interpretação pode ser compreendida como uma posição que não supõe propriamente a parceria entre professores da universidade e os da escola básica. Entretanto, com discursos desse mesmo ano e outros já formulados nos anos 2000, acreditamos ter mostrado indícios do quanto o envolvimento em pesquisas na área de educaça em ciências tem contribuído para descaracterizar a prescrição como possível solução para os problemas de ensino.

Outra questão pode ainda ser aqui lembrada. Mesmo que não oconam prescrições dirigidas direta ou indiretamente aos professores da educação básica é fato que nas produções dirigidas aos professores também podemos encontrar o que vamos aqui chamar de recomendações vazias. E o que consideramos uma recomendação vazia? Esta pode ser compreendida como aquela recomendação através da qual o professor recebe informações sobre resultados satisfatórios para determinados processos de ensino, sem que sejam apresentados os fundamentos desses procedimentos. Ou seja, o professor recebe informações sobre que conteúdo seria conveniente que ele ensinasse, ou sugestões de atividades ou recursos considerados propícios para suas aulas. Mas essas recomendações não vêm acompanhadas de características do conteúdo que justifiquem sua possível adoção.

Nesse tipo de recomendação também não se fala das teorias filosóficas, psicológicas, sociais ou pedagógicas que subentendem as recomendações e, no caso de estudos que tenham anteriormente sido realizados com grupos de estudantes, não são explicitadas para o professor as condições de produção do trabalho efetuado, nem são detalhados os procedimentos seguidos. Apenas são apontados os resultados do que foi feito.

Além disso, na recomendação aqui considerada vazia, não parece haver preocupação com as especificidades dos problemas que a recomendação visa solucionar. Ou seja, há comumente uma tendência a generalizar. E sabemos o quanto é importante o conhecimento detalhado de um problema para que possamos pensar em soluções possíveis. As características das situações escolares em que algo funciona ou deixa de funcionar, estão estritamente associadas aos limites e possibilidades do trabalho pedagógico. Já a recomendação vazia, freqüentemente é bastante genérica.

Acreditamos que, no que se refere a possíveis parcerias entre professores da escola básica e pesquisadores do ensino de ciências, principalmente aqueles que tenham, em suas pesquisas, focalizado a formação docente, a possibilidade de ocorrerem prescrições tende definitivamente ao esvanecimento, mas, para que também sejam superadas as recomendações vazias, é necessário que sejam mais valorizados e debatidos os apoios teóricos da pesquisa e suas condições de produção, do que propriamente os resultados obtidos, o que nem sempre ocorre.

Devemos ainda lembrar que, no que se refere ao ensino, os acontecimentos que relacionam professores e pesquisadores englobam apenas uma parcela mínima das políticas educacionais e ações relativas às escolas de um país. É apenas essa parcela que foi aqui discutida. Ainda que ela possa e deva ter influência nas políticas públicas e demais ações educativas, apenas o seu enfoque não resolverá todos os problemas relacionados à educação. 


\section{Bibliografia}

Almeida. Maria José P. M. (2006). Prescrições e recomendações ao professor na solução de problemas do ensino na Educação em Ciências. Ciência \& Ensina, vol.1, n.1, dezembro, p. 47-51.

(2003). Meio Século de Educacão em Ciências: uma leitura de recomendaçóes ao professor de física. Tese Livre Docência, Faculdade de Educação, Universidade Estadual de Campinas. Campinas, S. 111p.

Ciência e Cultura. V.41, n.3. p.264-269.

(1989). O Papel do Professor no Material para Ensino de Física.

Carvalho, Anna Maria Pessoa e Gil-Pérez, Daniel. (1993). Formação de Professores de Ciências: tendências e inovações. Trad. Sandra Valenzuela. São Paulo: Cortez Editora. [Coleção Questões da Nossa Época; v. 26, 120p.

Contreras, José. A (1999). Autonomia de Professores. São Paulo: Cortez Editora. 296p.

Gioppo, Christiane. A produção do saber docente no ensino de Ciências: uma proposta de intervenção. Curitiba: IBPEX, , 228p.

Giroux, Henry A. (1997). Os professores como intelectuais: rumo a uma pedagogia crítica da aprendizagem. Trad. Daniel Bueno. Porto Alegre: Artes Médicas. 270p.

Ianni, Octavio. (1986). O professor como intelectual: aultura e dependência. In: CATANI, Denise B.et al. (orgs.) Universidade, escola e formação de professores. São Paulo: Brasiliense p. 39-49.

Kincheloe, J. (1997). Joe A formação do professor como compromisso político: mapeando o pósmodemo. Trad. Nize Maria Campos Pellanda. Porto Alegre: Artes Médicas. 262p.

Krasilchik, Myriam (1987). O professor e o aumíallo das ciências. São Paulo: EPU: EDUSP, [Temas Básicos de Educação e Ensino], 80p.

Menezes, Luís Carlos (org.). (1996). Formação continuada de professores de ciências no âmbito ibero-americano. São Paulo: CEI, Editores Associados, Nutes. p.135-146.

Mion, Rejane Aurora e saito, Carlos Hiroo. (2001). Investigação-ação: mudando o trabalho de formar professores. Ponta Grossa: Gráfica Planeta. 148p.

Nardi. Roberto, bastos, Femando, Diniz, Renato Eugênio da Silva (Orgs.). (2004). Pesquisas em ensino de ciências: contribuições para a formação de professores. São Paulo: Escrituras. 254p.

Nardi, Roberto; Almeida, Maria José P.M. (2008). Educación en Ciencias: lo que caracteriza el área de enseñanza de las ciencias en Brasil según investigadores brasileños. Revista Electrónica en Educación en Ciencias. (REIEC, Argentina) V.3 p. 24-34.

(2007). Investigação em Ensino de Ciências no Brasil Segundo Pesquisadores da área: alguns fatores que lhe deram origem Pro-Posiģões (FE Unicamp), v.18, p.213-226.

Orlandi, Eni P. (1999). Análise de Discurso Princípios e Procedimentos. Campinas: Pontes. 100p. Vozes. 1995150p. Interpretação: autoria, leitura e efeitos do trabalho simbólico. Petrópolis: 
Tecné, Episteme y Didaxis: TE $\Delta$ No. Extraordinario, 2009

$4^{\circ}$ Congreso Intemacional sobre Formación de Profesores de Ciencias

Conferencias Centrales

Brasiliense. p.18-31.

(1983). A linguagem e seu funcionamento: as formas do discurso. São Paulo:

Rosa, Maria Inês Petrucci.(2004). Investigação e Ensino: articulações e possibilidades na formação de professores de Ciências. Ijuí : Editora Unijuí. [Coleção Educação em Química], 184p.

Selles, Sandra Escovedo e ferreira, Márcia Serra (Orgs.). (2003). Formação docente em Ciências. memórias e práticas. Niterói : EDUFF. 175p. 